on November 8, 1934, published in the March issue of the Institute's Journal, constituted an extremely valuable review of the more immediate past and future of metallurgical development. Under the title of "Recent Trends and Future Developments in Metallurgical Research", Dr. Moore surveyed the application of physical and physico-chemical methods to the study of metals and alloys, with particular reference to the industrial application of the results of research. In the period under review-the past decade-the output of metallurgical research has undoubtedly been unparalleled; but in Dr. Moore's view the main bulk of this large output has been concerned with the exploitation of fundamental concepts which had been developed more than ten years ago. Research in progress at the present time is reviewed under six main heads: melting and solidification, working of metals, heat treatment, mechanical properties, corrosion, and electro-deposition, and the directions in which work may be expected to proceed in the near future are outlined. The impression gained from this exceptionally interesting and virile address is one of boundless fields of research, offering fascinating possibilities in the extension of the use of metals for a very wide range of purposes for the benefit of civilisation.

\section{Science and Humanism}

Is the quest for a unity underlying the rich variety of the universe, philosophers are in constant danger of limiting themselves to unreal abstractions and verbal dialectic. Both those who call themselves pragmatists, as dealing with things rather than with words, and those who prefer the fuller name of humanists, find that science, the most objective of human experiences, has a large contribution to make to our general body of thought. As is pointed out by A. Rey in "Les Mathématiques en Grèce" (Actualités Scientifiques, 217. Paris: Hermann et Cie., 1935) the study of the history of science may be recommended on two grounds. It may make scientific thought more accessible to philosophers, and may do something to break down, among scientific workers themselves, that narrow specialisation which is so prevalent to-day. Among the ancient Greeks, as also in the Renaissance, both ages of humanism and free inquiry, science had a considerable place, though not an exclusive one. The humanism of to-day has at its disposal an embarrassing array of tempting dishes; the difficulty is to make a well-balanced selection from them, and to get the whole range of mental vitamins without suffering from hypervitaminosis.

\section{Description and Identification of Species}

IN spite of the three quarters of a million species of animals which have been described binomially, it is remarkable how little there is of organised plan in the descriptions, taken as a whole. Some authors of new species are content with a few lines of characterisation, others seem to describe, not a species, but the total characters of an individual specimen. It is partly that species are not fixed, and that few writers, even on the same group, would agree upon the characters to be selected as criteria of specific rank, partly that the critical characters within different groups appear to be so diverse, that no common plan would fit more than a relatively few. Dr. Séverin Icard has made a bold attempt to standardise descriptions of species by advocating a method which he calls "la méthode des nombres signalétiques" (Revue de Path. comp. Hyg. gen., Nov. 1934). It looks quite simple. Shortly, it is that, in regular order, parts of the specimen to be identified or described are examined, and the result for each part is represented by a number. The key to the parts to be examined for a particular group, and to the number corresponding to a particular character, say, legs yellow, is to be found in a set of "Tables de correspondance". Thus the special character of each part has its own particular number, a short-hand way of writing a description which normally would contain at least a few words for each part.

\section{Species Formula}

IN describing a beetle, for example, Dr. Icard chooses seven characters, always read in the same order-colour of thorax, colour of elytra, form of thorax, form of elytra, form of feet and tarsi, form of antennæ, form of head. Each character, in a particular specimen, is represented by a numberthe nombre signalétique or descriptive number, so that the total description of the specimen as regards specific characters may be represented by a series of numbers-the formule signalétique or specific formula. We wish to identify a beetle; we translate one by one its characters into the appropriate number; then having composed our specific formula we search for this particular formula in another book of words, "Le Répertoire général", and if we find the formula there we shall also find opposite it the name of the species which possesses this characteristic association of characters. It is an attractive idea that the plant and animal worlds should be so completely tabulated that a set of symbols would identify any of their members, and if the method would enforce upon describers of species definiteness in characterisation and brevity, it might be well worth a trial.

\section{Suggested Biological Survey for Union of South Africa}

IN the South African Journal of Science (Nov. 1934, p. 396), Dr. R. Bigalke makes a plea for the inauguration of a biological survey in the Union. During 1911-33 the Provinces spent $\mathfrak{f 6 0 7 , 6 7 4}$ in connexion with fish and game preservation and the destruction of vermin, and the suggestion is that a biological survey would furnish scientific information for the more efficient use of such expenditure. The survey would be a unit of the Department of Agriculture, and it would set in the forefront of its aims the solution of pressing economic problems, such as the biology and control of predatory animals, of noxious rodents, or rabies transmitters, and the relation of wild birds to agriculture. Before such 